\title{
Social Dimension of Media Space in the Age of Postmodernity
}

\author{
In the Context of Objective Knowledge Obtainment
}

\author{
Denis Chistyakov \\ "STREAM” Television Company”, CJSC \\ Moscow, Russia \\ E-mail: chistyakov.d@gmail.com
}

\begin{abstract}
The article is dedicated to the analysis of the actual problems of postmodern society connected to the communicative and informational mass-media space. The author reviews social specifics of society in the postmodern era defined by the endless torrents of mass-media information, images, symbols, and signs that lead to qualitative new social interactions. The author's special interest is the process of the self-identification and the problem of obtaining the objective knowledge in the postmodern epoch.
\end{abstract}

Keywords-mass-media; postmodern; social; objective knowledge; media information; simulacrum; hyper-reality

\section{INTRODUCTION}

While considering a postmodern society, it is required to proceed from the fact that a postmodern human being is involved in fundamental communicative relations differently than those of the modern era. A subject nowadays is found in the endlessly circulating torrents of information for the production and transmission of which were created means that even in definition reflect their purpose: "means of mass communication", "mass media". In the 1920s-1930s, "early" media structures (newspapers, magazines, movies, radio) as well as their products were being created for broad mass consumption. Let us stress that the very definitions of "mass media" and "mass communication" surface at the beginning of the $20^{\text {th }}$ century based on the importance to explain the new historical and social phenomenon - the modern world. Media as a communicative space grew gradually in its early period of crucial importance and claimed the essential foundation of a completely new society associated with the industrial development, national states establishment in their struggle against the empires, urbanization, new political and religious ideas etc. [1; P. 4]. Mass media was born in the context of socio-cultural transformations and contradictions in the international arena of the first quarter of the 20th century and remained deeply involved in the tradition of the Western national states cultural and social development.

\section{THE CHANGE OF MEDIA ROLE In CONTEMPORARY CULTURE AND EDUCATION}

Media by the beginning of the 20th century has undergone radical changes and are associated with globalization, information and technocracy of society.
Instead of the so-called "traditional" media, "new" media (Internet, mobile technologies, alternative informational and social networks) has emerged that constitute and define an individual's social life. The aforementioned individual is not only seized in the pervasive flow of information, but is also included in the very media production system that shapes the public consciousness while manipulating and creating the phenomena of the "public opinion" at the same time. That is often illusory, mythological, "hyperreal" in terms of the French philosopher Jean Baudrillard. The elite consumer, the lone person, who is analyzing the incoming information and reflecting on current events and facts is now an exception in the chain of media messages being created and transmitted.

The modern day has significantly changed the state of an individual, his way to work and how he perceives the world (i.e. reflexive forms of the knowledge obtained). Media products' effects on individuals are very specific. Generated media messages, images, symbols and signs not only form the basis of perception of social facts and processes, but also become a key to understanding the contemporary social reality and sometimes can even replace reality itself in an individual's mind. Therefore, society in its traditional sense, according to J. Baudrillard, is gradually being replaced by "cyber artificial limbs" - a virtual reality, comprised of dominative simulacra, simulations, imitating social interactions and illusive communication.

Significantly different from the previous era are the sense of inclusion in reality, self-identity and the significance of the self in a dynamically changing complex society. Postmodernity introduces a certain state of discord to the sense of stability, self-confidence, reliability and prospects of existence. Instead of traditional signposts (according to the choice of profession, education, moral and religious selfesteem, etc.) comes instability, chaotic dispersal of social roles, individualization and disintegration of the social space. An individual finds himself in a society where old relationships, connections and social patterns are wrecked, where the very definition of "values" is meaningless because of an infinite scattering, splitting and artificial artifacts' reproduction disappear criteria of values and axiological assessment. According to J. Baudrillard's figurative remark, 
culture, advertising and media reach in a described society a state of "Xerox" [2].

In the named context, an individual is forced to perform on a daily basis a variety of social roles akin to the social "games" characterized by the rapid and subtle rule and format changes. The aforementioned individual's success now depends on how quickly he is able to break his own behavioral patterns and to engage, adjust to the new rules that are accepted with no prior notice. Zygmunt Bauman notes: "The life success (and thus rationality) of postmodern people depends on the rate with which they manage to get rid of their old habits, rather than on gaining momentum. The best strategy is not to worry about life priorities; the habit is the lack of any habits" [3; P. 157].

\section{ON J-F. LYOTARD'S LANGUAGE-GAMES CONCEPT}

Postmodern society becomes more and more discrete, fragmented where unified logic fails. Human life is also fragmented: short life spans surface, presenting immediacy of present time with a set of personal goals and desire to achieve them. However, that immediacy, even futureoriented, can change at any time, become obsolete and insignificant. The erosion of social institutions, their deregulation and disintegration (the process, described by Jean-François Lyotard as "atomization" of the social in the era of "relaxation" [4]) leads to the constant and neverending search for self-identity, new ways of living, and new types of identity. It happens so fast and so often that human existence is transformed into some kind of life at a crossroads, a chain of chaotic events, where only extraordinary effort could help to achieve a desired goal. This "liquid" (Z. Bauman) state of society [5] with radically changed institutional features led to the fact that "social" in the postmodernity should be considered qualitatively from such a point of view, where social relations no longer maintain the nature of modernity relationships.

British sociologist N. Gain, describes postmodern society and notes: "It is impossible to interpret social relationship as a derivative form of human interaction (as did Marx and Weber), to reduce social interaction to face-to-face social agents interaction, or talk about society in the same vein". The scientist postulates the emergence of "post-human" which stands as an attribute of postmodernity. From his point of view, the post-human activities is inconceivable without intelligent machines. Technology increases its power over human to the extent that the latter can no longer be viewed as a sovereign "agent" of a society. The society and the individual at the same time lose their former social characteristics [6; P. 86].

J-F. Lyotard views postmodern in that regard as accomplished deep-laid changes to modernity, by which socio-cultural foundation of the world appears quite different than in the preceding era. Sociality in that world dissolves as direct communication among individuals and is replaced by the language models, a dense layer of information streams which switches off individuals from the social. In the process of transformation of the social, information, messages, signs, meanings, symbols, language and linguistic aspects take on new meanings and high significance. Society is being divided into atoms, forming the set of "flexible networks of language-games" (J-F. Lyotard). Through the languagegames models, social communication can legitimize itself and regain its lost pragmatic meaning. The atomized space (the society of "post-humans") largely exerts its efficiency and vitality under the influence of receiving and transmitting media information.

\section{J. BAUDRILLARD'S VIEW ON MEDIA}

Society appears to be firmly included into the informational communicative space, stipulating life system that can be conditionally referred to as "life according to the questionnaire". Social life is thus described by the constant flow of incoming messages to which it is necessary to reply. People live in the endless "referendum mode" (J. Baudrillard) that is not aimed at receiving profound knowledge and reflection or analysis of the aforementioned messages. Such state of the society is determined by contemporary media. Every given TV program, numerous political shows and talk shows, polls, debates, everyday functional advices etc. expressed through mass media appear as a form of question/answer even if it seems to be untraceable at first glance. J. Baudrillard rightfully pointed out: "The whole communication system has transformed from a complex syntactic structure of a language to a binary sygnaletic system "question/answer" (challenge and response) continuous testing system. Meanwhile it is known that the test and the referendum are sublime forms of simulation: the answer is suggested by the question, modeled in advance and designated by it" [2; P. 134].

As media is a major producer and supplier of information shaped in such a way that messages are predicting, impelling and sometimes imposing the answer to the set questions, and the issues discussed turn out to be predetermined, it turns out that media is the main producer of simulacra as well. Any emerging problem, conflict situation, social fact become "language-game" of the questions/answers. Reality is being tested by an individual who in turn is being tested by the reality. Since each message is a variation of code, the personal challenge now lies in decoding it. Decoding, however, appears as a diverse range of solutions: each person offers his vision of a problem, his interpretation of a message and makes a choice. Postmodern sociology argues that a personal way of communicating with the world around is similar to reading, "selective decoding", during which an individual is a subject to selection by media.

The semantic significance of the messages received is also determined by media. Information perception and processing is largely regulated by the means and methods carried out by the content selection, cutting, surveys to determine results. M. McLuhan expressed this whole process in his world-famous "Medium is the message" maxim. Public opinion is being formed gradually and systematically depending on the purpose of its formation and the level / degree of needed manipulative influence on the society. As a result, an individual nowadays has almost no possibility to distinguish objective reality from its simulation, imitation, and fine substitution. The problem of obtaining the true knowledge emerges as in the information society a gap 
between truth and lie is diminished, "the truth itself becomes a simulacrum" (J. Baudrillard).

The aforementioned theories are well-illustrated by the fact of the powerful influence Russian media has on the formation of public opinion towards the migrants and, as a result, the establishment of the stereotypical understanding of the migrants within Russian culture. The Russian philosopher Olga Chistyakova reviews the creation of media myths concerning the Others - migrants, foreigners, culturally completely different to the receiving culture, and who are largely linked to the existing economic and sociocultural problems of Russia. O. Chistyakova writes: «Thus in the modern-day Russian society the image of the Other - the Migrant of a different culture - is being created. Many economical and sociocultural problems are connected to these symbolical images of the migrants. The understanding of the face of the Other, a person of another culture and religion, depends mostly on the narration and submitting of media images of the migrants. Negative perception of the migrants is being constructed mostly because of the specific information found on them in both national and local media» [7; P. 57].

As a consequence of the formation of these illusory, simulative media myths, the problem of obtaining objective knowledge emerges, transmitting true knowledge of the current events. Let us emphasize that major media, largely doing a good cause, at least try to introduce objectivity, independence, reliability and stand their value and moral grounds. Moreover, the concept of "truth" as a set goal, is declared the standard of transmitted messages, news, information and symbolic reality $[1,8]$. However, it is practically impossible to recognize truth in a constant information flow and produced media messages. Most of all, this recognition possibility largely depends on the ambiguity of the multidimensional information packets, the diversity of interpretations, decoding of the transmitted messages, images and signs. As a matter of fact, media information, whatever forms it takes, leads to the infinity of subjective interpretations, uncertainty of the decoding means and discussion of the transmitted content received.

\section{The StATE of MEdia In CONTEMPORARy SOCIETY}

Media information in the postmodern condition enjoys a special power able to exalt an individual and to secure him an unprecedented social position. Prestigious status is acknowledged for those holding a large quantity of information and included in a larger number of communicative links. Information, according to $\mathrm{M}$. McLuhan, "extends outward man" to the point where "the creative process of learning will be collectively and corporately extended to the scale of the whole human society" [8].

Media reached the status of "mediacracy" (Régis Debray), a manifestation of power over individuals and society. Said power, as a special type, is impossible to deny and underestimate due to the fact that it becomes comprehensive and totally pervasive. Z. Bauman, stressing the importance of a change that affected media, has a status change of an individual in the era of "fluid postmodernity" compared to the "modernity" notes in his "The Individualized Society": "In the formation of hierarchies of influence, "renown" replaced "fame", public recognition forced out scientific diplomas; the process is not as much controlled, as pushed by the structures specializing in public relations management" [3; P. 160].

The grave impact of media, the manipulation of public opinion, the management of social communities and the instant obsolescence of fame and information transmitted, are - simultaneously - essential features and vices of our time. Media sets the rules under which an individual joins the run for fame and popularity realizing that, when achieved, they may turn out to be rather short-term. Strangely amusing is the fact that these rules and forms, in which the rising popularity is expressed, are the same for all: they average pop stars and businessmen, outstanding scholars, scientists and athletes, artists and housewives. Ulrich Beck assumed that it was the chaotic technology development (and may us add - media, transmitting messages) that abolishes the equals sign that was traditionally put between knowledge, culture, moral aspects of human coexistence and social and personal welfare.

\section{CONCLUSION}

A radical change of media structures, communication forms shaped the very foundation of postmodern culture. The culture of the book, printed form morphed into the culture of screen. Social relations in the audiovisual postmodern culture transform into human-machine relations. An individual lives in an imaginary world of screens, interfaces, programs and networks. The screen appears to be a text medium instead of writing, as it was the case in the previous, book culture. Screen culture with its own non-verbal language, can perform a "clean offering" of a reality with which an individual may interact without mediators. Such communications are not preceded by the verbalized knowledge so there is no reality transformation caused by language. An individual perceives reality beyond any prefaced language (as it was within the book culture with visuals and images serving as the basis of understanding the world in its diversity.

The postmodern world, in our opinion, is far more complex for a human to grasp than in any previous modern world. Social issues are being gradually replaced by technological ones as if forfeited by machines and the latest technological innovations. Society lives in a sign-symbolic environment filled with a world of images, simulations, and imitations. Cyberspace and virtualization blur the boundaries between real life and simulation and between objective reality and its illusory image. Yet, an individual shall save himself and secure his mind in the "almost real" world.

\section{REFERENCES}

[1] McQuail Denis. McQuail's Mass Communication Theory. (6th edition). SAGE Publications Ltd. NY, 2011. - p. 619.

[2] Baudrillard J. Symbolic Exchange and Death. M.: DOBROSVET. 2009. - p. 387.

[3] Bauman Z. The Individualized Society. M.: Logos, 2005. - p. 390. 
[4] Lyotard J-F. The Postmodern Condition. M., SPb.: Aleteiia, 1998. p. 160.

[5] Bauman Z. Liquid Modernity. SPb.: Piter, 2008. - p. 240.

[6] XVI World Congress of Sociology. Abstracts. ISA 2006 Congress. The Quality of Social Existence in a Globalization World. - Durban South Africa: Guide to Discovery, 2006. - p. 618.

[7] Chistyakova O. Media Myth Influence on «Other» Culture Formation in Russian Society (in the Context of External Migration) // Science Almanac of Black Sea Region Countries. 2015. № 1.

[8] McLuhan M. Understanding Media: The Extensions of Man. M.: KANON-PRESS-Ts., 2003. - p. 464. 